\title{
Exposure Total Volume Administration Unit
}

National Cancer Institute

\section{Source}

National Cancer Institute. Exposure Total Volume Administration Unit. NCI Thesaurus.

Code C83037.

The unit of measure for the gross volume of the apportioned exposure. 